\title{
85. Observation on Prolonged Posttraumatic Disturbance of Consciousness
}

\author{
Ikuzo Yokoyama, Sumitaka Tokito, Toshio Nakayama, Yoshihide Hasegawa \\ Kazuo Kinzyo, Shiro Imamura, Hideji Go, Junichi Shral \\ and Akira YoкотA \\ 1st Dept. Surgery, Kumamoto Univ., School of Medicine \\ Yoshiaki IEIRI \\ 2nd Dept. Pathology, Kumamoto Univ., School of Medicine
}

Twenty-four cases with prolonged posttraumatic unconsciousness which lasted for a period of more than 3 weeks following head injury were analyzed.

In all but one of the cases craniotomies were performed and it was revealed that 18 cases had large intracranial hematomas and 5 cases showed cerebral lacerations with marked cerebral edema. None of the cases with intracranial hematoma showed lucid-interval. In all the patients severe disturbance of consciousness was observed since immediately after head injury. Prolonged posttraumatic unconsciousness in these patients might be attributed mainly to lesions in the brain stem; the primary lesions in the brain stem might be superimposed by secondary lesions in the brain stem resulted from intracranial hematoma and/or cerebral edema.

In 6 cases, disturbance of consciousness recovered without any gross mental deficit and the improvement in the state of consciousness commenced on the 29 th posttraumatic day on the average. In contrast, 11 cases gained consciousness, with some extent of neurological and/or mental deficit and the improvement in the state of consciusness in this group commenced on the 40th posttraumatic day on the average; at the latest on the 60 th. Six patients, who did not gain consciousness until the 60th posttraumatic day, continued to live in a vegetative state, the average survival term being 149 days.

Prognosis of disturbance of consciousness in these patients was extremely difficult to be decided. In patients with favorable clinical course, nucleic acid derivatives administered prior to improvement in the state of consciousness sometimes produced imprevement in EEG findings. Because such a change in EEG as this was not observed in the patients who continued to be in a vegetative state, administration of nucleic acid derivatives might give some clue to evaluate the prognosis of prolonged posttraumatic unconsciousness. 